\title{
NARRATIVIZANDO FORMAÇÕES DOCENTES ENTRE CULTURAS DA MÍDIA E DA MEMÓRIA*
}

\author{
Marlécio Maknamara
}

\begin{abstract}
Cada vez que eu tentei fazer um trabalho teórico, foi a partir de elementos de minha própria experiência: sempre em relação com processos que eu vi desenrolar em torno de mim. É porque pensei reconhecer nas coisas que vi, nas instituições às quais estava ligado, nas minhas relações com os outros fissuras, abalos surdos, disfunções que eu empreendia um trabalho, alguns fragmentos de autobiografia. Não sou um ativista recuado que hoje gostaria de retomar o serviço. Meu modo de trabalho não tem mudado muito, mas o que eu espero dele é que continue ainda a me mudar.
\end{abstract}

Foucault - Entrevista - Ditos e Escritos IV

O ano é 2020 e jornais locais ainda se encantam com professores/as que se vestem de palhaço/a, de heróis/heroínas e/ou fazem aulas-show. Colegas docentes (em quantidade menor, talvez, do que se esperaria) inflamam-se e começam a contestar, nas redes sociais, dizendo que "a tarefa docente não é entretenimento". Seguem-se algumas linhas de argumentação para fazer um reclame: a aprendizagem não tem nada a ver com o que os professores aparentam e a quem estuda caberia "cumprir seu papel". Será?

Pessoa querida, você sabia que até mesmo a beleza de quem ensina tem interferido na avaliação que fazem do nosso trabalho (WOIClEKOVSKI; VIEIRA, 2020)? Quero dizer, portanto, que, mesmo concordando que as tarefas de ensinar venham sendo constituídas dentro de uma profissão que procura afirmar-se distinta de outras (da de animador/a de plateias, por exemplo), é inegável que essa mesma profissão vem sendo disputada também por conhecimentos, valores e expectativas que extrapolam as ordens e limites estabelecidos em práticas de formação e atuação reconhecidas ou tornadas reconhecíveis como legítimas, adequadas, corretas.

Quando necessidades de beleza ou de ludicidade ou de empreendedorismo ou de... (complete a lista!) infernizam a rede discursiva da su-

"DOI - 10.29388/978-65-86678-66-6-f.37-54 
posta sagrada, imaculada e angelical profissão, é porque há outras vontades de verdade sobre a docência. Há alguns anos meu foco tem sido abordar essas vontades de verdade sobre os sujeitos da educação escolar, particularmente os efeitos discursivos de diferentes artefatos culturais sobre a divulgação e a constituição de posições de sujeito. Aqui, objetivarei retomar e ampliar alguns elementos dessa problematização da produção cultural de sujeitos.

Focalizarei dois tipos particulares de cultura, aqueles que mais têm chamado minha atenção: a cultura da mídia e a cultura da memória, instâncias culturais inseridas naquilo que Hall (1998) chama de "novos tempos", ao tentar capturar o contexto de "profundas mudanças de caráter social, econômico, político e cultural em curso nas sociedades capitalistas ocidentais" (HALL, 1998, p. 14). Esses novos tempos demandam atenção à "condição problemática da subjetividade na atualidade" (BIRMAN, 2000). Tal condição "impõe a os/as educadores/as a necessidade de estudos que articulem o educacional, o social, o histórico e o psicológico, que tratem da conexão entre aprendizagens e modos de ser sujeito, que não subestimem os liames entre processos de subjetivação e as variadas instâncias do pedagógico" (MAKNAMARA, 2011, p. 15). Aquela atenção e o reconhecimento dessa necessidade continuam me mobilizando também em práticas de pesquisa e de formação em cursos de licenciatura.

Organizarei meu texto nos seguintes blocos, após esta introdução: o primeiro abordará cultura e estudos culturais em perspectiva pós-crítica, para descrever o que entendo por cultura da mídia e cultura da memória; o segundo bloco, mais propositivo, argumentará sobre possibilidades metodológicas para acessar vidas demandadas por artefatos da cultura da mídia e da memória, culminando com alguns elementos éticos e estéticos que podem advir desse tipo de problematização; em seguida, trago minhas considerações finais a partir da discussão realizada dentro dos limites deste texto.

\section{Cultura e Estudos Culturais em perspectiva pós-crítica}

Este texto tem inspiração teórico-metodológica nas teorias póscríticas em educação. As teorizações pós-críticas em educação no Brasil ganham espaço quando, nos idos da década de 1990, problematizam-se as transformações na economia, na política e na cultura para focalizar reestru- 
turações que o neoliberalismo, movimentos sociais e viradas epistemológicas vinham provocando na educação. "Colisão entre o velho e o novo", "dissoluções de fronteiras", "introdução de mecanismos de mercado na educação", "estado de revolução cultural", "ambientes de profusão e saturação de imagens", "estímulos ao consumo cultural", "revoluções teóricas e epistemológicas" - alguns dos termos usados à época para falar das transformações que impactavam a sociedade e pressionavam reestruturações na escola, no currículo e no trabalho docente - ajudaram a inteligir "uma vira da epistemológica radical" que estava a redimensionar princípios, métodos e procedimentos da teorização social e educacional (SILVA, 1997).

Desde então, se as teorias pós-críticas significam crítica e recusa a formas canônicas de conhecimento, por outro lado implicam em acolhida, experimentação e legitimação de formas alternativas que assumem e privilegiam o dissidente, o local, o parcial e o provisório nos processos de conhecer em educação. As teorias pós-críticas em educação operam também com uma noção ampliada de "cultura", de tal modo que é possível estender o pedagógico para além dos muros escolares e considerar que diferentes artefatos têm currículo, exercem pedagogias e produzem sujeitos. Os discursos acionados pelos mais distintos artefatos culturais ajudam a constituir textos curriculares, pois "quando informações, aprendizagens, sentimentos e pensamentos são articulados, está-se compondo o texto de um currículo" (MAKNAMARA, 2020, p. 59), o qual "não é simplesmente um texto: é um texto de poder" (SILVA, 2001, p. 67). Isso interessa à formação docente: como textos, artefatos culturais são textos curriculares, ao se compreender currículo como qualquer forma de organização de conhecimentos "envolvidos numa economia do afeto que busca produzir certo tipo de subjetividade e identidade social" (SILVA, 2002, p. 136).

Parte dessa ampliação é tributária dos Estudos Culturais, campo que emerge como um conjunto de movimentações teórico-políticas que se opõem às concepções elitistas e hierarquizantes de cultura (se entendida como processo estético, intelectual ou espiritual). Tais movimentações apontam para as possibilidades de o "cultural" ser abordado como qualquer terreno em que significados são compartilhados e no qual se lute por sua imposição em meio a relações de poder. Nesse sentido, "cultura" pode ser "uma prática discursiva envolvida na produção de significados, de regimes de verdade e de sujeitos de determinados tipos" (PARAíso, 2006a, p. 9), enquanto artefatos culturais resultam de um processo de construção e vincu- 
lação de significados culturais a diferentes objetos constituídos material e simbolicamente em uma cultura (CAMOZZATO, 2018).

Em sua vertente pós-estruturalista, os Estudos Culturais entendem cultura como "nada mais do que a soma de diferentes sistemas de classificação e diferentes formações discursivas aos quais a língua recorre a fim de dar significado às coisas" (HALL, 1997, p. 29). Materializada também em diferentes artefatos da cultura, a prática de significar "é fazer valer significados particulares, próprios de um grupo social, sobre os significados de outros grupos, o que pressupõe um gradiente, um diferencial de poder entre eles" (SILVA, 2001, p. 23). Práticas de significação são formas de exercício de poder, portanto. Para ver o poder em ação em diferentes artefatos culturais, tenho focalizado os discursos dos quais esses artefatos são produtos e produtores, entendendo discurso como "prática articuladora de elementos por meio dos quais efeitos de poder são traduzidos em fabricações de sujeitos" (MAKNAMARA, 2020, p. 63), já que o poder deixa marcas do seu exercício nas mais diferentes instâncias e práticas sociais, sendo o discurso uma dessas práticas.

\section{Modos de acessar, na licenciatura, vidas demandadas por artefatos culturais}

Os discursos acerca dos novos tempos, ainda que carentes de precisão e repletos de ambiguidades, estimulam a abertura de um debate acerca de transformações na sociedade e novas descrições e análises sobre as condições sociais a que determinados grupos estão sujeitos (HALL, 1998). Nesses novos tempos, subjetividades são importantes alvos de investimento e tornam-se mais segmentadas, fluidas, cambiantes: as pessoas agora operam em uma diversificada trama de universos sociais (HALL, 1998). Aqui, tomarei a cultura da mídia e a cultura da memória como termômetro desse novo quadro social, como sintoma de suas intensividades e extensividades.

Para Hall (1997), a mídia constitui uma das principais instâncias culturais pelas quais circulam ideias e imagens vigentes na contemporaneidade. Nesse cenário cultural, "há uma cultura veiculada pela mídia cujas imagens, sons e espetáculos ajudam a urdir o tecido da vida cotidiana" (KELLNER, 2001, p. 9) e que tem servido de "pano de fundo onipresente e muitas vezes de sedutor primeiro plano para o qual convergem nossa atenção e nossas atividades" (p. 11). Uma cultura que "passou a dominar a vida cotidi- 
ana" (KELLNER, 2001, p. 11) e que tem fornecido "os modelos daquilo que significa ser homem ou mulher, bem-sucedido ou fracassado, poderoso ou impotente" (KELLNER, 2001, p. 9). Contudo, nas palavras de Fischer (2003), a mídia não veicula somente, mas também constrói discursos e significados sobre modos de ser. Portanto, ainda que a cultura da mídia diga respeito ao "assalto das imagens, mensagens e espetáculos da mídia que inundam nossa cultura" (KELLNER, 2003, p. 107), não se deve desconsiderar a tarefa de entendê-la em seu caráter produtivo no que concerne aos processos de subjetivação engendrados em meio aos discursos por ela veiculados.

Em outra vertente de acesso aos "novos tempos" discutidos por Stuart Hall, entendo e uso a meu favor "cultura da memória" a partir de Sarlo (2007): como uma forma de organização do passado segundo procedimentos específicos de narrativas que valorizam o subjetivo; um modo peculiar de valorização e narração do passado que recorre à primeira pessoa, às suas lembranças e à experiência própria; uma tendência a reconstituir as verdades e texturas das vidas através da reivindicação do subjetivo, da revalorização da primeira pessoa como ponto de vista, da rememoração de experiências. Sarlo situa essa cultura da memória como efeito ou sintoma (que ela objetiva examinar em seu livro) de uma confiança social na primeira pessoa que narra sua vida "para conservar a lembrança ou para reparar uma identidade machucada" (SARLO, 2007, p. 19). Mas em educação as contrapartidas dessa cultura da memória têm sido outras.

No Brasil, especificamente, há, pelo menos, trinta anos tem-se recorrido a narrativas para pesquisar e formar docentes (LIMA, GERALDI e GERALDI, 2015), com especial destaque para pesquisas narrativas de cunho (auto)biográfico, centradas na experiência vivida. Nos tempos em que a vida das pessoas anseia exaustivamente por exposição e atração de público (SARLO, 2007; SIBILIA, 2008), não deixa de ser curioso que o campo educacional tenha reconhecido o falar de si não apenas como algo desejável, mas sobretudo como necessidade. Assim, os objetos das pesquisas (auto)biográficas têm sido tomados sob distintas perspectivas teórico-metodológicas (PASSEGGI, 2017) e os resultados das análises têm estimulado edital (BRASIL, 2015) e agendas de pesquisa nas CHSSALLA (OLIVEIRA, 2019), eventos científicos (PASSEGGI e SOUZA, 2017), práticas de formação (PASSEGGI e SOUZA, 2011) e de reorientação profissional (JOSSO, 2010), proposições curriculares (GOODSON, 2017).

Artefatos da cultura da mídia e da cultura da memória são alvo privilegiado de estratégias de regulação da vida, de condução da conduta. Im- 
plicados em conduzir condutas, artefatos culturais produzem sujeitos e exercem governo, afinal "aquilo que faz com que um corpo, gestos, discursos e desejos sejam identificados e constituídos enquanto indivíduos é um dos primeiros efeitos de poder" (FOUCAULT, 2007a, p. 183). As variadas capacidades de tais artefatos em seduzir e interpelar por meio da escrita, do canto, do movimento, da dança, da ativação de reminiscências de memórias, evidenciam aquilo que Foucault (2007b, p. 8) diz sobre o poder: que ele só é aceito e se mantém porque "produz coisas, induz ao prazer, forma saber, produz discurso".

Para captar esse caráter "positivo" do poder, é necessário ater-se às suas sutilezas presentes no material empírico e deixar o artefato cultural em questão falar sobre os tipos de sujeitos que ele tem desejado constituir. Nesse sentido, já tive oportunidades de colocar em cena algumas das maquinações de artefatos culturais em torno da produção de sujeitos generificados (2009a, 2009b, 2010a, 2016), da produção de modos de ser docente (2010b), da produção discursiva da natureza em desenhos animados (2015) e da produção de modos de fazer educação ambiental (2012). Detalhei passos metodológicos em Maknamara (2014) e os ampliei em Maknamara (2020).

Mas como introduzir e operar com essa discussão em situações de sala de aula em cursos de licenciatura?

\section{Ética da problematização com artefatos culturais midiáticos}

Em se tratando de acessar, conhecer e analisar vidas que são disponibilizadas e demandadas por artefatos da cultura da mídia e da cultura da memória, tenho me inspirado das teorizações de Michel Foucault acerca do sujeito. $O$ pensamento de Foucault traz as possibilidades de buscar em diferentes práticas sociais as condições pelas quais posições de sujeito são disponibilizadas em meio a relações de poder. É disso que se trata quando procuro problematizar a produção de sujeitos na cultura da mídia e na cultura da memória. Mas de que tipo de problematização estou a falar?

O foco dessa problematização de inspiração foucaultiana é cercar e apreender "o conjunto das práticas discursivas ou não-discursivas que faz alguma coisa entrar no jogo do verdadeiro e do falso e o constitui como objeto para o pensamento (seja sob a forma de reflexão moral, do conheci- 
mento científico, da análise política etc.)" (FOUCAULT, 2004, p. 242). Nesse sentido, então, problematizar é mostrar que algo que desponta no mundo está sendo alvo de regulação social em dado momento:

Como e por que certas coisas (comportamento, fenômenos, processos) tornaram-se um problema? Por que, por exemplo, determinadas formas de comportamento foram caracterizadas e classificadas como "loucura", enquanto outras formas similares foram completamente negligenciadas em um dado momento histórico? A mesma coisa para o crime e a delinqüência. A mesma pergunta de problematização para a sexualidade (FOUCAULT, 2013, p. 113).

Problematização, então, é uma forma de pensar. E quando se pensa assim, em que tipo de coisas é possível pensar? "Nas coisas de que não se é absolutamente senhor, que é preciso girar, rodopiar, sessenta e seis vezes no mesmo sentido antes de conseguir compreender. É isso que se pode chamar de pensamento. Ao cogitar, eu agito, eu vasculho. Isso só começa a ficar interessante quando é responsável, isto é, traz uma solução o máximo possível formalizada" (LACAN, 2006, p. 77). É nesse sentido que procuro problematizar a produção de sujeitos na cultura da mídia e na cultura da memória, seja em situações de desenvolvimento e orientação de pesquisa, seja em situações de sala de aula em cursos de formação docente. Entendo que nem os artefatos dessas instâncias culturais, tampouco os tipos de sujeitos cuja produção eles incitam, são naturais, óbvios, inevitáveis. E se uma problematização assim envolve pensar com responsabilidade e formalização, problematizar também pode ser uma atitude investigativa. Nesse sentido, fazer problematização é engendrar certa atitude de pesquisa. Que atitude é essa? Uma atitude crítica diante das coisas do mundo, uma atitude crítica que reverbera nas delimitações de nossos objetos e trajetos de pesquisa e formação. Mas o que seria "crítica", afinal?

Ora, "uma crítica não consiste em dizer que as coisas não estão bem como estão. Ela consiste em ver sobre que tipos de evidências, de familiaridades, de modos de pensamento adquiridos e não refletidos repousam as práticas que aceitamos" (FOUCAULT, 2010, p. 356). Ou ainda: "a crítica é o movimento pelo qual o sujeito se dá o direito de interrogar a verdade sobre seus efeitos de poder e o poder sobre seus discursos de verdade. Bem, então!: crítica será a arte da insubordinação voluntária, da indocilidade refletida" (FOUCAULT, 2007c, p. 47). Vê-se, portanto, que faz-se pro- 
blematização ao se fazer um tipo particular de crítica: uma crítica pautada no esquadrinhamento do que é dado como banal, como autoevidente ou como aceitável, baseado em tipologias, descrições e composições de pensamentos, de certezas e de mobilizações de desejos e práticas.

Problematização constitui direcionamento de pesquisa e por isso poderia, talvez, ser vista como metodologia. Como abordagem metodológica, uma problematização de inspiração foucaultiana pode explorar localizações de algo em jogos discursivos do verdadeiro e do falso, ao entender que as coisas do mundo são sem essência, que não são préexistentes à sua entrada na linguagem; que todo pensamento tem uma história; que as tarefas dos dizeres verdadeiros é um empreendimento infindável e submetido a vontades de saber-poder. "Problematizar uma questão se inscreveria decididamente, então, numa perspectiva eminentemente genealógica" (BIRMAN, 2010).

Minha prática pedagógica em cursos de licenciatura tem sido orientada, também, por essa noção de problematização. Problematizar tem sido um encaminhamento, especificamente em disciplinas voltadas aos estudos culturais, para explorar conexões entre cultura midiática e educação. Nessas disciplinas, é comum a dificuldade inicial em compreender os sentidos em que artefatos culturais midiáticos se fazem pedagógicos: sobre a tv, por exemplo, alunos/as aproximam-se do debate dizendo que "a função pedagógica da tv ainda não é suficientemente explorada pelas escolas". Verdade, mas não apenas em sentido didático, sentido de "usar a televisão como recurso para educar, motivar os alunos e transformar as aulas em lugares de conhecimento diferenciado".

Ainda que a função didática da tv e de outros artefatos culturais não venha sendo explorada a contento, o centro da argumentação em tais disciplinas é o de que a tv já ensina às nossas crianças, a despeito disso ser reconhecido ou aproveitado em sala de aula. Ou seja: a tv segue ensinando ainda que não seja aproveitada "devidamente" pelas escolas. As pedagogias exercidas pela tv são ainda mais instigantes quando se sabe que as crianças brasileiras são as que mais passam tempo vendo $t v^{1}$, enquanto o tempo médio anual dessa exposição vem aumentando ano após ano ${ }^{2}$. Em síntese, trata-se de argumentar que a tv tem uma função pedagógica não pelo seu potencial didático, mas por suas formas de influenciar nossa cultura e, portanto, nossas vidas. As problematizações que fazemos em aula seguem as

\footnotetext{
${ }^{1}$ Disponível em: encurtador.com.br/kqC48. Acesso em: 30 out 2020.

${ }^{2}$ Disponível em: encurtador.com.br/nozF0. Acesso em: 30 out 2020.
} 
pistas dadas por Woodward (2008), para quem todo artefato cultural regula a vida social conectando suas formas de representação, articulação e consumo e as identidades e subjetividades a eles associadas.

Nos componentes curriculares que tenho ministrado em diferentes cursos de licenciatura, problematizamos uma gama de práticas e de artefatos culturais midiáticos sob inspiração de Foucault, para quem "há sempre um pouco de pensamento, mesmo nas instituições mais bobas, há sempre pensamento, mesmo nos hábitos mudos" (2010, p. 356). É produtivo, então, garimpar esse pensamento, sentir o(s) "princípio(s) de inteligibilidade" que está(ão) em jogo em um artefato cultural, ou seja, "a idéia que regula um exercício particular de poder, uma maneira de pensar, analisar e definir os elementos que, em sua natureza e relações, concorrem para efeitos específicos de poder" (MAKNAMARA, 2011, p. 132). Tenho insistido nisso nas pesquisas que tenho desenvolvido e orientado, tenho exercitado isso em disciplinas das licenciaturas.

\section{Estética da inscrição na confecção de artefatos culturais memorialísticos}

Outra frente de exercício da noção de problematização em cursos de licenciatura tem sido a da escrita. Entendo que escrever um texto acadêmico inclui, mas vai além de, anunciar, criar e explicitar um pacto entre quem escreve e quem lê. Consiste em forjar afinidades e ensejar compromissos entre quem redige o texto e quem poderá vir a ler o mesmo. Um texto é um instrumento teórico e político que, como tal, se insere em uma rede discursiva, seja no seu tecer ou no seu desfiar, tensionando-a e concorrendo para sua permanente recomposição. Seja em situações de formação inicial, seja em situações de pesquisa, entendo que escrever um texto acadêmico, guarda, portanto, possibilidade de ampliação de possíveis e de produção e disponibilização de beleza no mundo.

Tenho compreendido, também, que para produzir conhecimento com vidas que circulam em diferentes artefatos culturais é produtivo procurar fugir de certo modo dominante de racionalidade e de escritas. "Feminizar é preciso", disse Margareth Rago (2001), a favor de uma cultura filógina, em oposição às racionalidades androcêntricas que norteiam práticas científicas, políticas e sexuais e a todo um imaginário misógino que ainda subsiste, apesar de uma inegável "falência dos modos cêntricos - falo-euro-etno- 
cêntricos - de agir e pensar". Em se tratando de pesquisas pós-críticas em educação, isso também se traduz em um estilo de escrita no qual é inevitável ocupar um lugar de fala particular. Estilo que aponta para uma tentativa de aproximações entre pensamentos, desejos, intenções, compreensões e (por que não?) emoções. Afinal, "quando a narrativa se separa do corpo, a experiência se separa de seu sentido" (SARLO, 2007, p. 27).

Isso porque nos modos canônicos de produzir conhecimento "não há razão da experiência, não há linguagem da experiência, por muito que essas formas de racionalidade façam uso e abuso da palavra experiência" (LARROSA, 2014, p. 40). Nesses modos canônicos de pesquisa e de escrita, a ciência "captura a experiência e a constrói elaborada e expõe segundo seu ponto de vista, a partir de um ponto de vista objetivo, com pretensões de universalidade" (LARROSA, 2014, p. 40). Não à toa, a linguagem adotada por esse tipo de estudo é uma língua de sujeitos sem língua que não se dirigem a ninguém: uma "língua neutra e neutralizada da qual se apagou qualquer marca subjetiva” (p. 59), uma língua que não diz respeito a ninguém e que não pode ser nossa (pelo menos não a minha!), já que é uma língua sem sujeito falante e sem sujeito ouvinte, uma linguagem que não se estabelece entre sujeitos.

Fugir dessa racionalidade inclui adotar uma outra linguagem para falar do conhecimento que está em jogo e é um exercício desafiador que tenho procurado experimentar com meus/minhas estudantes e orientandes. Em um dos últimos textos de sua carreira como pesquisador no campo da educação, Tomaz Tadeu da Silva (2004) nos propõe um questionamento: "por que, aparentemente, o estilo não tem sido um problema na escrita educacional?". Penso que essa pergunta tem tudo a ver com nossas tarefas de docentes e de pesquisadores/as, já que Tomaz coloca o problema do estilo na escrita educacional em termos de conexões entre pensamento, política e vida.

Trata-se, em suma, de compreender que a escrita pós-crítica em educação é parcial e subjetiva. Minha forma de atentar a tudo isso tem sido a de procurar perseguir uma escrita viva, uma escrita com vida, uma escrita que convide, uma escrita convidativa, uma escrita que dispare sensações, que potencialize minha vida pelo menos naquilo que me faz sentir criativo pois, penso eu, não há maior prova de vitalidade do que a criatividade: criar é da ordem da vida, criar é do mundo dos vivos, só o que está vivo pode criar (MAKNAMARA, 2020). 
Para tanto, ao lidar com a leitura ou com a construção de narrativas (auto)biográficas, é primordial oferecer-se a captar sensações e surpresas provocadas pelos encontros com os universos existenciais que elas sugerem. É instigante atentar àquilo que, do contato com o material empírico lido ou produzido, movimenta o pensamento. É produtivo seguir as pistas deixadas por combinações particulares de fragmentos das escritas de si (extraídas de narrativas de cada sujeito com quem se pesquisa ou produzidas de narrativas acessadas a partir de cada posição de sujeito que habitam em nós mesmos/as) e das imagens que delas podem vir a emergir. Trata-se de fazer pesquisa e formação com narrativas tomando a escrita como uma poética, um modo de fazer e dar a ver, uma artesania, um produto das artes do fazer.

Com base em Silva (2004) e em Guacira Louro (2007), afirmo que buscar um estilo próprio de escrita pós-crítica em educação não é uma questão de ordem acessória nem dependente somente de uma vontade individual. Como já disse outra vez, trata-se de decidir fazer o escrito reverberar o fluxo da vida porquanto qualquer modo de escrita articula-se às escoIhas teórico-políticas de quem escreve. Nesse sentido, parece ser potente trabalhar a escrita como inscrição, deixando claro por meio de nossos textos "como nos apresentamos, como nos colocamos no mundo e como gostaríamos que nossos objetos fossem apresentados em suas múltiplas conexões com outros objetos e conceitos" (MAKNAMARA, 2014, p. 168-169).

Vê-se, portanto, que uma estética da inscrição, seja na confecção, seja na interpretação de artefatos da cultura da memória, sinaliza para a admissão de leituras muito particulares de narrativas (auto)biográficas, representando certo tipo de capacidade e esforço no sentido de manusear o material (escrito com diferentes propósitos, sob circunstâncias diversas), acessar os elementos que se deseja e Ihes conferir uma inteligibilidade particular. Também considero importante ressaltar que, seja na leitura ou na construção de narrativas (auto)biográficas, trata-se de um fazer muito particular também porque inevitavelmente marcado pelo lugar de enunciação de quem as lê ou de quem as produz, pelos discursos que lhe atravessam e que lhe constituem sujeito em múltiplas posições. Desconsiderar ou fazer pouco de lugares de enunciação é o mesmo que assumi-los vazios, uma pretensão inevitavelmente imperialista e colonizadora (CORNEJO, 2011, p. 80). Nesse sentido, na análise ou na produção das narrativas (auto)biográficas, é importante enfatizar mais uma vez a compreensão de que a pesquisa e a escrita pós-crítica em educação é parcial e subjetiva (MAKNAMARA, 2014). 


\section{Considerações finais}

O campo educacional nunca mais foi o mesmo após as teorias póscríticas lhe provocaram abertura. Ao conferir centralidade à linguagem na construção da vida social, as teorias pós-críticas em educação destacam que vivemos imersos em um emaranhado de relações e práticas sociais engendradas discursivamente e colocam em evidência os variados artefatos e processos que atribuem sentidos a lugares, coisas, fenômenos, práticas e sujeitos. Isso faz assumir que não há sujeito fora ou antes de um discurso que lhe corresponda, um discurso que o posicione como indivíduo assujeitado a esse mesmo discurso, discurso que cuide sistematicamente para forjar um sujeito a quem aparentemente apenas se refere quando tal discurso diz o que diz sobre tal sujeito.

Para o pensamento pós-crítico, a questão fundamental da linguagem não é a figuração (com um sentido empirista em que palavras simplesmente corresponderiam a coisas) nem a mediação (com um sentido pragmático em que caberia à linguagem fazer a mera troca de significados entre sujeitos): a questão fundamental da linguagem nas teorizações pós-críticas é a criação - aqui, a linguagem não é decalque nem troca, a linguagem é truque, é produção de sentidos e verdades. Por conseguintes, as teorizações pós-críticas em educação têm me proporcionado abordar as vidas dos sujeitos da educação em termos de como elas são produzidas discursivamente, como são produzidas em meio a discursos cuja textualidade dá-se no seio de diferentes culturas.

Procurei dar alguma contribuição para ilustrar o alargamento proporcionado pelos efeitos combinados de diversas teorizações que vêm configurando o pensamento pós-crítico no campo educacional. Para me aproximar metodologicamente dos efeitos discursivos de diferentes artefatos culturais sobre a constituição de posições de sujeito, meu objetivo foi retomar e ampliar elementos de uma problematização da produção cultural de sujeitos da educação. As discussões que trouxe buscaram reforçar que artefatos midiáticos e memorialísticos, artes feitas na cultura da mídia e na cultura da memória, forjam sujeitos porque têm currículo, um produto da disponibilização de formas de raciocínio, saberes, valores, afetos e comportamentos que contribuem, através de estratégias e técnicas específicas, para a formação de pessoas ao atribuir significados a lugares, coisas, fenômenos, práticas e sujeitos. 
Artefatos culturais envolvem-se na produção de sujeitos por meio de diversificadas estratégias discursivas. Eles disponibilizam linguagens para falar dos e para os sujeitos e sistemas conceituais para calcular capacidades e condutas e calibrar a psique. Os diferentes artefatos das culturas da mídia e da memória podem ser lidos como textos: composições linguísticas que, mais que mediar e comunicar relações entre palavras e coisas, incorporam, produzem e disponibilizam significados, saberes, valores. Textos produzem, disponibilizam e incitam formas particulares de ver, saber, sentir e descrever e, assim, concorrem para processos de subjetivação. As análises discursivas empreendidas por Foucault possibilitam uma apropriação de textos oriundos das mais diferentes instâncias sociais, no sentido de colocar em cena as maquinações pelas quais somos fabricados como tipos particulares de sujeitos.

No que diz respeito à cultura da mídia, em outro exercício de apropriação das ideias foucaultianas em torno do sujeito, da linguagem e do poder, recentemente publiquei artigo (MAKNAMARA, 2020a) abordando conexões entre educação e cultura da mídia a partir dos estudos curriculares de orientação pós-crítica. Por meio da noção de "currículo cultural" extraescolar e partindo do pressuposto de que um currículo tem "vontade de sujeito" e produz subjetividades, retomei e ampliei discussões e resultados obtidos anteriormente em minha Tese para argumentar que, quando um artefato cultural articula informações, aprendizagens, sentimentos e pensamentos, está compondo o texto de um currículo. Sintetizei procedimentos metodológicos e resultados de pesquisa para ilustrar como um artefato cultural aparentemente inócuo pode ser investigado e significado como máquina de ensinar, como artefato que governa e produz sujeitos.

No que diz respeito à cultura da memória, pesquisas (auto)biográficas produzidas ou analisadas sob inspiração pós-crítica também trazem de produtivo a possibilidade de aprofundar nossas ferramentas de análise para melhor compreender e explicar como, afinal, narrativas (auto)biográficas ensejam processos formativos e potencializam mudanças na relação que sujeitos estabelecem consigo e com outros. E uma vez que fazer história diz respeito às "artes de inventar o passado" (ALBUQUERQUE JÚNIOR, 2007), tenho entendido "memória" como um jogo de significações entre a materialidade, as potencialidades e a ficcionalidade de fatos do vivido. Assim, tenho lido e feito ler narrativas (auto)biográficas no sentido de captar "as múltiplas possibilidades de um discurso em termos das coisas ditas" (MAKNAMARA, 2011), entendendo que o material empírico dá a ver as sutilezas 
de poder enquanto aparentemente apenas testemunha ditos e feitos de quem escreve sobre si. Tenho procurado instalar a mim ou a outros/as no espaço-entre, no meio daquilo que as escritas de si oferecem e abrem como possibilidade, ou seja, procurar apreender o discurso em seu poder de afirmação.

\section{Referências}

BIRMAN, Joel. A problemática da verdade na psicanálise e na genealogia. Tempo psicanal. Rio de Janeiro, v. 42 , n. 1, p. 183-202, 2010.

BIRMAN, Joel. Subjetividade, contemporaneidade e educação. In: CANDAU, Vera (Org.). Cultura, linguagem e subjetividade no ensinar e aprender. Rio de Janeiro: DP\&A, 2000, p. 11-28.

BRASIL. Memórias Brasileiras: biografias. Edital n. 13/2015. Diário Oficial da União. Brasília, ano CLII, 29 jul. 2015. Seção 3. P. 33.

CAMOZZATO, Viviane C. Sociedade pedagógica e as transformações nos espaços-tempos do ensinar e do aprender. Em Aberto. Brasília, v. 31, n. 101, p. 107-119, 2018. DOI: http://dx.doi.org/10.24109/21766673.emaberto.31i101.3526.

FISCHER, Rosa M. B. O dentro e o fora da recepção: por uma análise da heterogeneidade dos processos comunicacionais. In: FRANÇA, Vera; WEBER, Maria H.; PAIVA, Raquel; SOVIK, Liv. (Orgs.). XI COMPÓS - 2002. Porto Alegre: Sulina, 2003, p. 371-384.

FOUCAULT, Michel. Discurso e verdade: seis conferências dadas por Michel Foucault, em Berkeley, entre outubro e novembro de 1983, sobre a parrhesia. Prometeus: filosofia em revista, São Cristóvão, n.6, v.13, edição especial, p. 1-114, 2013.

FOUCAULT, Michel. É importante pensar?. In: MOTTA, Manoel Barros da (Org.). Repensar a política. Rio de Janeiro: Forense Universitária, 2010, p. 354-358. 
FOUCAULT, Michel. Soberania e disciplina. In: MACHADO, Roberto (Org.).

Microfísica do Poder. 23. ed. Rio de Janeiro: Graal, 2007a, p. 179-191.

FOUCAULT, Michel. Verdade e poder. In: MACHADO, Roberto (Org.). Microfísica do Poder. 23. ed. Rio de Janeiro: Graal, 2007b, p. 01-14.

FOUCAULT, Michel. What is critique?. In: FOUCAULT, Michel. The politics of truth. Los Angeles: Semiotext(e), p. 41-81, 2007c.

FOUCAULT, Michel. O cuidado com a verdade. In: MOTTA, Manoel Barros da (Org.). Ética, sexualidade, política. Rio de Janeiro: Forense Universitária, 2004, p. 240-251.

GOODSON, Ivor. The rise of the life narrative. In: GOODSON, Ivor (Org.). The Routledge international handbook on narrative and life history. NY: Routledge, 2017, p. 11-22.

HALL, Stuart. O significado dos Novos Tempos. Margem. São Paulo, n. 07, p. 13-29, 1998.

HALL, Stuart. A centralidade da cultura: notas sobre as revoluções culturais do nosso tempo. Educação \& Realidade. Porto Alegre, v. 22, n. 02, p. 15-46, 1997.

JOSSO, Marie-Christine. Da formação do sujeito... ao sujeito da formação. In: NÓVOA, António; FINGER, Matthias (Orgs.). 0 método (auto)biográfico e a formação. Natal: EDUFRN, 2010, p. 59-79.

KELLNER, Douglas. A cultura da mídia - estudos culturais: identidade e política entre o moderno e o pós-moderno. Bauru: EDUSC, 2001. 454 p.

KELLNER, Douglas. Lendo imagens criticamente: em direção a uma pedagogia pós-moderna. In: SILVA, Tomaz Tadeu da (Org.). Alienígenas na sala de aula: uma introdução aos estudos culturais em educação. Petrópolis: Vozes, 2003, p. 104-131. 
LIMA, Maria E. C.; GERALDI, Corinta M.; GERALDI, João. O trabalho com narrativas na investigação em educação Educação em Revista. Belo Horizonte, v. 31, n. 1, p. 17-44, 2015.

LOURO, Guacira L. Conhecer, pesquisar, escrever... Educação, Sociedade \& Culturas. Porto, n. 25, p. 235-245, 2007.

MAKNAMARA, Marlécio. Quando artefatos culturais fazem-se currículo e produzem sujeitos. Reflexão e Ação, Santa Cruz do Sul, v. 27, p. 58-72, 2020a.

MAKNAMARA, Marlécio. O que Joana e Janaína têm a ensinar para o ensino de Biologia. In: CHAVES, Silvia; AMORIM, Antonio C.; GASTAL, Maria; BASTOS, Sandra; FERREIRA, Márcia Serra (Orgs.). Vidas que ensinam o ensino da vida. São Paulo: LF, 2020b, p. 27-42.

MAKNAMARA, Marlécio. Breve narrativa sobre a experiência de ser monstr@. In: CHAVES, Sílvia N.; SILVA, Carlos A. F.; BRITO, Maria dos R. (Orgs.). Cultura e subjetividade: perspectivas em debate. 1ed.São Paulo: Editora Livraria da Física, 2016, v. 1, p. 195-213.

MAKNAMARA, Marlécio. Natureza e desenhos animados: conexões com a formação docente em ciências. Alexandria (UFSC). Florianópolis, v.8, p.75 87, 2015.

MAKNAMARA, Marlécio. Afinidades e afinações pós-críticas em torno de currículos de gosto duvidoso In: PARAísO, Marlucy A.; MEYER, Dagmar E. E. (Orgs.). Metodologias de pesquisas pós-críticas em educação. 2. ed. Belo Horizonte: Mazza, 2014, p. 155-174.

MAKNAMARA, Marlécio. "NEM PARECE O NORDESTE": (des)serviços da educação ambiental ao dispositivo pedagógico da nordestinidade. In: PREVE, Ana M.; GUIMARÃES, Leandro B.; BARCELOS, Valdo; LOCATELLI, Julia S. (Orgs.). Ecologias inventivas: conversas sobre educação. Santa Cruz do SulRS : EDUNISC, 2012, p. 199-212. 
MAKNAMARA, Marlécio. Novos tempos para as feminilidades e masculinidades. Tenda da Lua. Belo Horizonte, p. 2 - 2, 01 jun. 2010a. Disponível em: http://clinicadofeminino.com.br/img/tenda\%20da\%20lua_3.pdf. Acesso em: 30 nov 2016.

MAKNAMARA, Marlécio. Fim dos enigmas para a boa docência? Cinform. Aracaju, p. 2 - 2, 24 maio 2010b. Disponível em: http://www.ufs.br/conteudo/3075-fim-dos-enigmas-para-a-boa-doc. Acesso em: 30 nov 2016.

MAKNAMARA, Marlécio. O forró eletrônico e a educação nossa de cada dia (II). Cinform. Aracaju, p. 2 - 2, 22 jun. 2009a. Disponível em: http:// www.ufs.br/conteudo/2998-o-forr--eletr-nico-e-a-educa-- . Acesso em: 30 nov 2016.

MAKNAMARA, Marlécio. O forró eletrônico e a educação nossa de cada dia (I). Cinform. Aracaju, p. 2 - 2, 15 jun. 2009b. Disponível em: http:// www.ufs.br/conteudo/2999-o-forr--eletr-nico-e-a-educa-- . Acesso em: 30 nov 2016.

MAKNAMARA, Marlécio. Currículo, gênero e nordestinidade: o que ensina o forró eletrônico? 2011. 151f. Tese (doutorado) - Faculdade de Educação, Universidade Federal de Minas Gerais, Belo Horizonte, 2011.

OLIVEIRA, Mayra Juruá G. Diagnóstico da situação atual das CHSSALLA brasileiras. Brasília: Centro de Gestão e Estudos Estratégicos, 2019. 246 p.

PARAíSO, Marlucy A. A(s) cultura(s) no GECC: artefato, objeto de estudo e conceito. In: AMORIM, Antonio Carlos R. de; PESSANHA, Eurize (Org.). As potencialidades da centralidade da(s) cultura(s) para as investigações no campo do currículo. Caxambu: GT Currículo da ANPED, p. 07-13, 2006.

PASSEGGI, Maria da C. Autobiographical narratives in education. Auto/Biography Studies, v. 32, p. 293-295, 2017.

PASSEGGI, Maria da C.; SOUZA, Elizeu C. de. Movimento (auto)biográfico no Brasil: esboço de suas configurações no campo educacional. Investigacion Cualitativa, Urbana, v. 2, p. 6-26, 2017. 
PASSEGGI, Maria da C.; SOUZA, Elizeu C. de. (Auto)biografia e educação: pesquisa e práticas de formação. Educação em Revista, Belo Horizonte, v. 27, p. 327-332, 2011.

RAGO, Margareth. Feminizar é preciso: por uma cultura filógina. São Paulo em Perspectiva, São Paulo, v. 15, n. 3, p. 58-66, 2001.

SARLO, Beatriz. Tempo passado: cultura da memória e guinada subjetiva. São Paulo: Companhia das Letras; Belo Horizonte: UFMG, 2007.

SIBILIA, Paula. O show do eu. Rio de Janeiro: Nova Fronteira, 2008. 286 p.

SILVA, Tomaz Tadeu da. Educação pós-crítica e formação docente. Cadernos de Educação, Pelotas, v. 8, p. 155-170, 1997.

SILVA, Tomaz Tadeu da. $\mathbf{O}$ currículo como fetiche: a poética e a política do texto curricular. 2. ed. Belo Horizonte: Autêntica, 2001. 120 p.

SILVA, Tomaz Tadeu da. Documentos de identidade: uma introdução às teorias do currículo. 2. ed. Belo Horizonte: Autêntica, 2002. 154 p.

SILVA, Tomaz Tadeu da. A golpes de estilo. In: MOREIRA, Antonio; PACHECO, José; GARCIA, Regina. (Org.). Currículo: pensar, sentir, diferir. Rio de Janeiro: DP\&A, 2004. p. 215-223.

WOICIEKOVSKI, Edinéia; VIEIRA, Alboni Marisa. A manifestação do "Prêmio de Beleza" na área de Ensino. Debates em Educação, Maceió, v. 12, n. 27, p. 200-213, jun. 2020. ISSN 2175-6600. Disponível em: https://www.seer.ufal.br/index.php/debateseducacao/article/view/8912. Acesso em: 29 jul. 2020. doi: https://doi.org/10.28998/2175-6600.2020v12n27p200-213.

WOODWARD, Kathryn. Identidade e diferença: uma introdução teórica e conceitual. In: SILVA, Tomaz Tadeu da. (Org.). Identidade e diferença: a perspectiva dos estudos culturais. 8. ed. Petrópolis: Vozes, 2008, p. 07-72. 